\title{
Glibenclamide-Associated Hypoglycaemia: A Report on 57 Cases
}

\author{
K: Asplund ${ }^{1}$, B.-E. Wiholm ${ }^{2,3}$ and F. Lithner ${ }^{1}$ \\ ${ }^{1}$ Department of Medicine, Umeå University Hospital, Umeå, \\ ${ }^{2}$ Department of Drugs, National Board of Health and Welfare, Uppsala and \\ ${ }^{3}$ Department of Clinical Pharmacology, Karolinska Institute, Huddinge Hospital, Huddinge, Sweden
}

\begin{abstract}
Summary. In the largest series of patients with glibenclamideassociated hypoglycaemia reported so far, 51 cases reported to the Swedish Adverse Drug Reactions Advisory Committee and six additional cases are reviewed and related to sales and prescription data of glibenclamide. Median age of the patients with hypoglycaemia was 75 years and $21 \%$ were 85 years or above. For comparison, the median age of a random sample ( 1 in 288 of all patients prescribed glibenclamide) was 70 years and only $5 \%$ were 85 years or older. In eight out of 40 cases where duration of glibenclamide treatment was recorded, the hypoglycaemic event occurred during the first month of treatment. The median daily dose of glibenclamide prescribed was $10 \mathrm{mg}$ both in the hypoglycaemic cases and in the prescription sample. Coma or disturbed consciousness was the most common clinical presentation in this series and the minimum blood glucose value was $1.3 \mathrm{mmol} / \mathrm{l}$ (median). Twenty-two
\end{abstract}

patients responded immediately to treatment, 24 had protracted hypoglycaemia of $12-72 \mathrm{~h}$ duration and 10 died. Fatal outcome was observed even with small doses of glibenclamide $(2.5-5 \mathrm{mg} /$ day). Previous strokes and cardiac disorders were isolated as two independent determinants of a serious course of the hypoglycaemia. Other contributing factors included impaired renal function, low food intake, diarrhoea, alcohol intake and interaction with other drugs. Thus, it is not uncommon for glibenclamide, like the first-generation sulphonylureas, to cause serious, protracted and even fatal hypoglycaemic events.

Key words: Sulphonylurea, glibenclamide, drug-induced hypoglycaemia, hypoglycaemic coma, drug-related death, drug interactions
The value of sulphonylureas in the long-term treatment of Type 2 (non-insulin-dependent) diabetes has been questioned [1]. The potential benefits of an oral antidiabetic drug must be carefully weighed against the risk of hazardous adverse reactions, hypoglycaemia in particular. In 1972, Seltzer reviewed more than 200 cases of severe hypoglycaemia induced by sulphonylureas [2]. Of these, the majority were attributed to chlorpropamide. During the last decade, newer, more potent sulphonylurea preparations have been introduced. There have been only few reports on severe hypoglycaemic events caused by these agents and, therefore, little is known about the salient features of hypoglycaemia induced by the so-called second generation of sulphonylureas. The biological half-life of single doses of glibenclamide is relatively short $[3,4]$. Therefore, when the drug was first marketed, it was inferred that hypoglycaemia induced by glibenclamide might be less common and easier to control than that induced by chlorpropamide.
In Sweden, glibenclamide was introduced in 1971 and it is now the most frequently prescribed oral antidiabetic drug [5]. Up to mid-1981, a total of 51 reports on hypoglycaemia in glibenclamide-treated diabetic patients, including 10 cases with fatal outcome, had been submitted to the Swedish Adverse Drug Reactions Advisory Committee (SADRAC).

This report outlines some clinical characteristics of these 51 patients and also of six additional cases, not reported to SADRAC. Sales and prescription data on glibenclamide are also analysed as background information.

\section{Patients and Methods}

In Sweden, adverse drug reactions have been reported to SADRAC of the National Board of Health and Welfare since 1965. From 1975, reporting is compulsory for suspected reactions that are fatal or otherwise serious, new, unexpected or remarkable. In the present study, we examined all 51 reports on glibenclamide-associated hypoglycaemia 


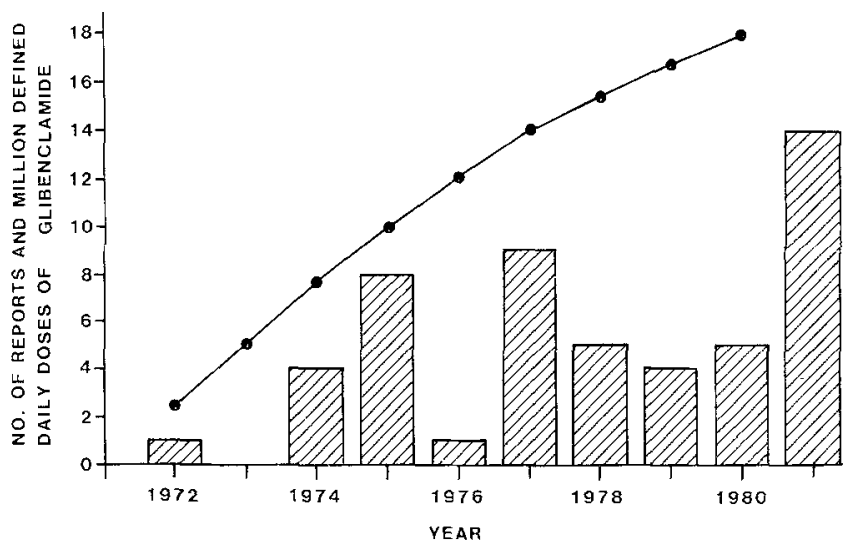

Fig.1. Annual numbers of glibenclamide-associated hypoglycaemic episodes reported and sales of glibenclamide in Sweden [5]. The defined daily dose of glibenclamide is $10 \mathrm{mg}$ [6]. Only first 6 months of 1981

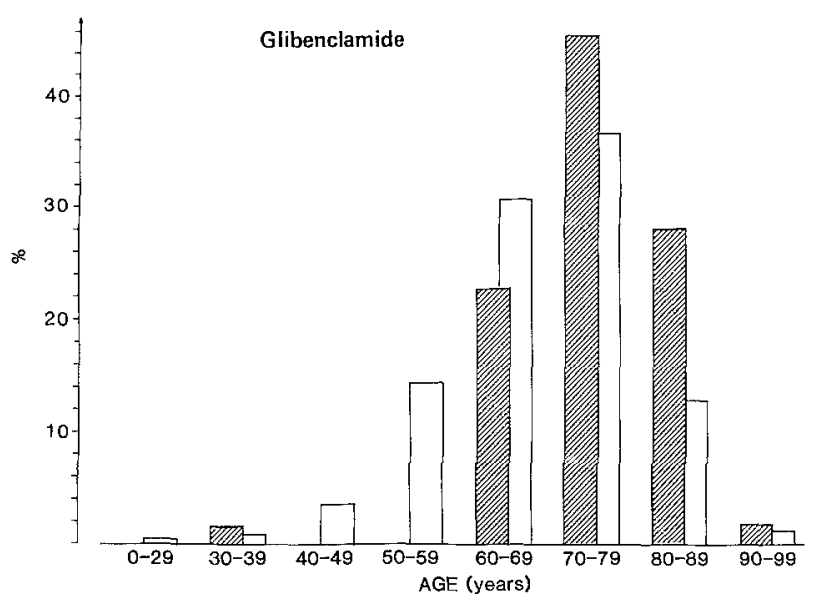

Fig. 2. Age distribution of 57 patients with glibenclamide-associated hypoglycaemia 7 ;istribution of patients from the prescription survey $1975-1980 \square$ (annual sample size, mean $=593, \mathrm{SD}=71$ )

Table 1. Time since diagnosis of diabetes mellitus and duration of glibenclamide treatment in 57 patients with glibenclamide-associated hypoglycaemia

\begin{tabular}{lcc}
\hline Duration & \multicolumn{2}{c}{ Number of patients } \\
\cline { 2 - 3 } & Diabetes & $\begin{array}{l}\text { Glibenclamide } \\
\text { treatment }\end{array}$ \\
\hline$<1$ month & 7 & 8 \\
$1-3$ months & 4 & 8 \\
$4-12$ months & 9 & 14 \\
$1-5$ years & 13 & 10 \\
$>$ 5 years & 19 & 0 \\
Data not available & 5 & 17 \\
\hline Total & 57 & 57 \\
\hline
\end{tabular}

that were classified as 'probable' or 'possible'. To clarify details in the reports, complete medical records were obtained. During the course of our work, we became aware of six additional cases of glibenclamide-associated hypoglycaemia not reported to SADRAC. These cases are also included in this report.

The diagnosis of hypoglycaemia (blood glucose $<2.5 \mathrm{mmol} / \mathrm{l}$ ) was based on blood glucose determinations by a glucose oxidase method and concomitant clinical symptoms in 54 events occurring in 50 patients. In the remaining seven cases, all had symptoms suggestive of hypoglycaemia and responded promptly to the administration of intravenous glucose. Blood glucose was determined quantitatively in five of them, showing moderately low levels $(2.8-3.0 \mathrm{mmol} / \mathrm{l})$ and semi-quantitatively by Dextrostix in one instance. Five patients were concomitantly treated with biguanides.

Total annual sales of glibenclamide in Sweden [5] were converted to and expressed as numbers of so-called defined daily doses [6]. For glibenclamide one defined daily dose is set to $10 \mathrm{mg}$.

Since 1974, age and sex of the patient and name and amount of the drug have been recorded from a random 1-in-288 sample of all prescriptions delivered in Sweden [7]. Since 1976 the prescribed daily dose has also been recorded. Data from this prescription survey have been extracted and compared with age, sex and daily dose of the patients with hypoglycaemia. Between 1975 and 1980, a total of 3,557 prescriptions of glibenclamide was recorded and the annual sample size averaged 593 with a standard deviation of 71 .

\section{Results}

Reporting to the Swedish Adverse Drug Reactions Advisory Committee

Figure 1 gives the sales of glibenclamide and the annual number of hypoglycaemic episodes reported to SADRAC.

There is a great variation in the reporting from year to year and a marked geographical clustering in the reporting which does not correspond to differences in sales (data not shown).

\section{Patients}

There was a female preponderance both among the patients with hypoglycaemia (61\%) and in the prescription material (55\%). Median age was 70 years among the 57 hypoglycaemic patients and 75 years among the 3,557 patients from the prescription survey (Fig. 2). The proportions of patients aged 85 years or more were $21 \%$ and $4.8 \%$ respectively $(p<0.01)$. Only one of the hypoglycaemic patients was $<60$ years of age.

As shown in Table 1, diabetes was diagnosed during the 12 months preceding the index event in more than one-third of the patients and during the last month in seven. However, one-third had diabetes of more than 5 years' duration.

\section{Glibenclamide Treatment}

Data on the duration of glibenclamide treatment were available in 40 patients. Of these, 30 individuals had been on glibenclamide for $<1$ year. In eight cases hypoglycaemia developed within the first month and in four cases within the first week of glibenclamide treatment.

The prescribed daily doses of glibenclamide in the patients with hypoglycaemia and in the prescription survey are displayed in Figure 3. The distributions of daily doses were similar and median daily dose was $10 \mathrm{mg}$ in both groups. 


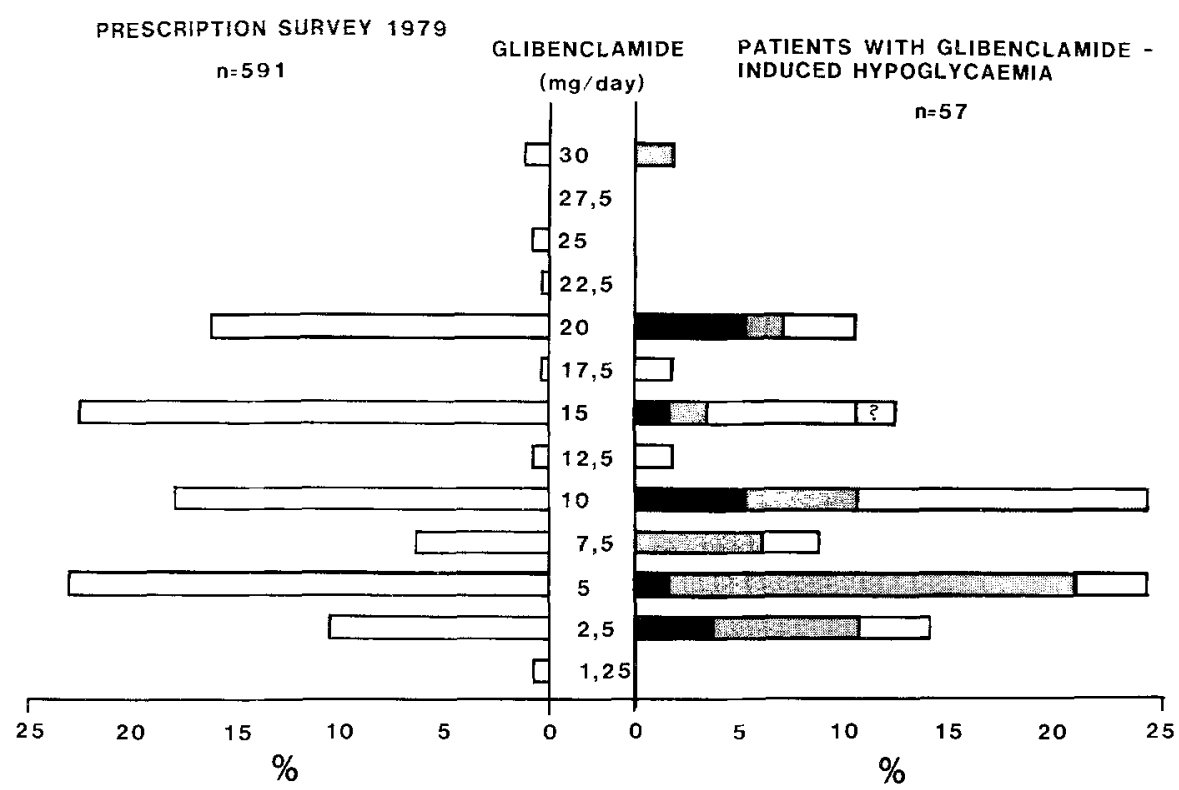

Fig.3. Distribution of prescribed daily doses of glibenclamide as related to outcome of the hypoglycaemic event (right-hand part of the figure). $\square=$ short duration $(<12 \mathrm{~h})$,,$=$ protracted hypoglycaemia $(12-72 \mathrm{~h}),=$ death, ? = surviving, but duration unknown. For comparison, prescribed daily doses of glibenclamide in the prescription survey 1979 are shown on the left. $n$ denotes number of patients

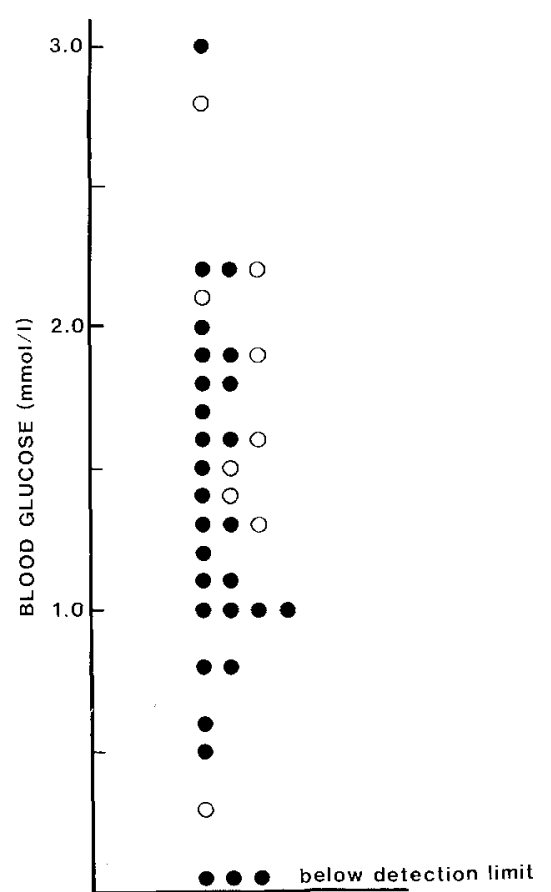

Fig.4. Minimum blood glucose recorded during 54 hypoglycaemic events in 50 patients. $=$ patients with coma or precoma, $\bigcirc=$ patients with other clinical presentations (see text for details)

\section{Clinical Features of Hypoglycaemic Events}

The lowest blood glucose value recorded in each case is shown in Figure 4 (median $1.3 \mathrm{mmol} / \mathrm{l}$ ). The hypoglycaemic incidents were attended by coma or disturbed consciousness in 46 of the 57 diabetic patients. The 11 remaining patients presented with sudden onset of confusion, impairment of speech, extreme fatigue or excessive sweating. As shown in Figure 4, blood glucose levels overlapped in patients with and without coma.

Three principal courses of the hypoglycaemic events emerged from the medical records: (1) 22 patients res- ponded immediately to therapy and did not relapse; (2) 24 patients had protracted hypoglycaemia of at least $12 \mathrm{~h}$ duration, two of these remained hypoglycaemic for 3 days despite continuous IV glucose therapy; (3) ten patients had deep coma leading to death. The duration of hypoglycaemia was not stated in one non-fatal case.

The clinical notes were seldom sufficient to determine whether the patients were left with sequelae to the hypoglycaemic event. The youngest patient (aged 32 years), however, was left with permanent brain dysfunction after a protracted hypoglycaemic coma.

Among the ten cases with fatal outcome, one died within a few hours of the onset of hypoglycaemia. Eight had hypoglycaemia lasting for at least $12 \mathrm{~h}$ despite correct diagnosis and treatment with parenteral glucose. When the hypoglycaemia was alleviated they all remained comatose until death which occurred within 1-20 days. Autopsy was performed in six of these ten patients. In support of a metabolic catastrophe, gross examination failed to determine the immediate cause of death in any of these cases.

\section{Contributing Factors}

The medical records were also reviewed for other factors possibly contributing to the hypoglycaemia (Table 2). Impaired kidney function with plasma creatinine levels of $126-516 \mu \mathrm{mol} / 1$ (upper normal limit $100 \mu \mathrm{mol} / 1$ for men and $80 \mu \mathrm{mol} / 1$ for women) was noted in 12 patients. Two patients suffered from alcoholic liver cirrhosis, one had severe heart failure with liver congestion and jaundice, and one additional patient had enhanced bromsulphthalein retention of obscure origin. Cardiac disorders, including a history of heart failure, myocardial infarction or arrhythmia requiring treatment, had been diagnosed in 32 patients. Nine patients had a history of cerebrovascular accident and 17 were on treatment for hypertension. A preceding period 
Table 2. Course of glibenclamide-associated hypoglycaemia in 57 patients in relation to possible contributing factors. In 13 patients two or more of the contributory factors were present

\begin{tabular}{|c|c|c|c|c|c|}
\hline \multirow{2}{*}{$\begin{array}{l}\text { Contributing } \\
\text { factor }\end{array}$} & \multicolumn{5}{|c|}{ Course of hypoglycaemia } \\
\hline & $\begin{array}{l}\text { Rapid re- } \\
\text { sponse to } \\
\text { therapy }\end{array}$ & $\begin{array}{l}\text { Pro- } \\
\text { tracted }\end{array}$ & Death & $\begin{array}{l}\text { Un- } \\
\text { known }\end{array}$ & Total \\
\hline \multicolumn{6}{|c|}{ Numbers of patients with } \\
\hline $\begin{array}{l}\text { Abnormal } \\
\text { hepatic function }\end{array}$ & 0 & 2 & 2 & 0 & 4 \\
\hline $\begin{array}{l}\text { Abnormal } \\
\text { renal function }\end{array}$ & 3 & 4 & 5 & 0 & 12 \\
\hline $\begin{array}{l}\text { Decreased food } \\
\text { intake }\end{array}$ & 4 & 5 & 0 & 0 & 9 \\
\hline Diarrhoea & 2 & 3 & 0 & 0 & 5 \\
\hline Alcohol intake & 1 & 1 & 0 & 0 & 2 \\
\hline Drug interaction & 6 & 9 & 6 & 1 & 22 \\
\hline $\begin{array}{l}\text { No obvious con- } \\
\text { tributing factor }\end{array}$ & 10 & 7 & 1 & 0 & 18 \\
\hline
\end{tabular}

of diarrhoea was noted in five and reduced food intake in nine patients.

Drugs taken together with glibenclamide are listed in Table 3. In accordance with the observed high prevalence of cardiac disorders and hypertension, many of the patients were treated with cardiac glycosides and/or diuretics. A sizable portion $(8 / 57)$ were on drugs with an anticholinergic action. Among drugs previously implicated in sulphonylurea-associated hypoglycaemia, salicylates $(12 \%)$ and biguanides $(9 \%)$ were most often encountered. It was notable that the combination of trimethoprim and a sulphonamide (sulphamethoxazole or sulphadiazine) was used in seven cases of glibenclamide-associated hypoglycaemia.

Alcohol was documented to be a contributory factor in two patients.

\section{Determinants of the Clinical Course}

When we explored the possible determinants of the course of the hypoglycaemic events it was, unexpectedly, found that younger age conferred a worse prognosis. Thus, in patients with fatal outcome median age was 68 years, in patients with protracted hypoglycaemia 74 years, and in those responding immediately to therapy 79 years. On the other hand, sex did not appear to predict the clinical course.

As demonstrated in Figure 3, there was no simple relation between prescribed daily doses of glibenclamide and clinical outcome. In patients with prompt response to therapy median daily dose was $10 \mathrm{mg}$, in those with protracted hypoglycaemia $5 \mathrm{mg}$ and in patients with a fatal outcome $10 \mathrm{mg}$. Protracted hypoglycaemia and death occurred also in patients treated with small doses of glibenclamide (2.5-5 $\mathrm{mg}$ daily).
We found no apparent common deleterious factor in patients with fatal outcome (except lower age than average, see above). However, several factors of possible importance for the outcome of the hypoglycaemic event were often present concomitantly. Multiple regression analysis was therefore performed to identify the major determinants. Immediate recovery upon therapy was tested against a severe course (protracted hypoglycaemia or death). Previous cerebrovascular accidents and cardiac disorders were identified as two statistically significant determinants of a severe course of the hypoglycaemia $(p<0.05)$; the regression coefficients were 0.46 and 0.36 , respectively. In this analysis, age was found to be negatively correlated with a severe course $(p<0.05)$. None of the other factors tested - impaired liver function, impaired renal function, alcohol intake, low food intake, diarrhoea, hypertension and intake of drugs known to interact with sulphonylureas reached statistical significance. However, the sensitivity of the analysis was limited due to the small number of positive observations in some of the variables.

\section{Discussion}

The 57 patients included in this report probably represent only a minority of all hypoglycaemic episodes caused by glibenclamide. It has been estimated previously that about $30 \%-40 \%$ of serious haematological adverse reactions are reported to SADRAC in spite of the regulations $[8,9]$. In the present study we found that six out of 12 cases from one hospital region were not reported. Moreover, there was a marked geographical skewing in the reports on glibenclamide-associated hypoglycaemia and little correlation in the temporal profile between the sales of glibenclamide and the number of hypoglycaemic episodes reported. Interestingly, 14 cases were reported to have occurred during the first half of 1981 after preliminary results of the survey had been presented orally. Therefore, our data do not permit any firm conclusions on the real incidence of hypoglycaemia attending glibenclamide treatment. Our presentation serves rather to define some clinical characteristics of this complication.

In 1972 and 1979 Seltzer reviewed a total of 778 episodes of drug-induced hypoglycaemic coma $[2,10]$. Sulphonylureas, alone or in combination with other hypoglycaemic or potentiating drugs, were responsible in 465 cases. Chlorpropamide, the most frequently prescribed agent, was involved more often than other sulphonylureas. Since these surveys were compiled, glibenclamide has become widely used and several reports on glibenclamide-associated hypoglycaemic coma have appeared. A search of the literature yielded another 55 cases of documented hypoglycaemia with coma or disturbed consciousness published between 1964-1980 [2, 11-26]. Including the present series, 101 severe hypoglycaemias, 14 with a fatal outcome, have been pub- 
Table 3. Concomitant drug intake in 57 cases of glibenclamide-associated hypoglycaemia

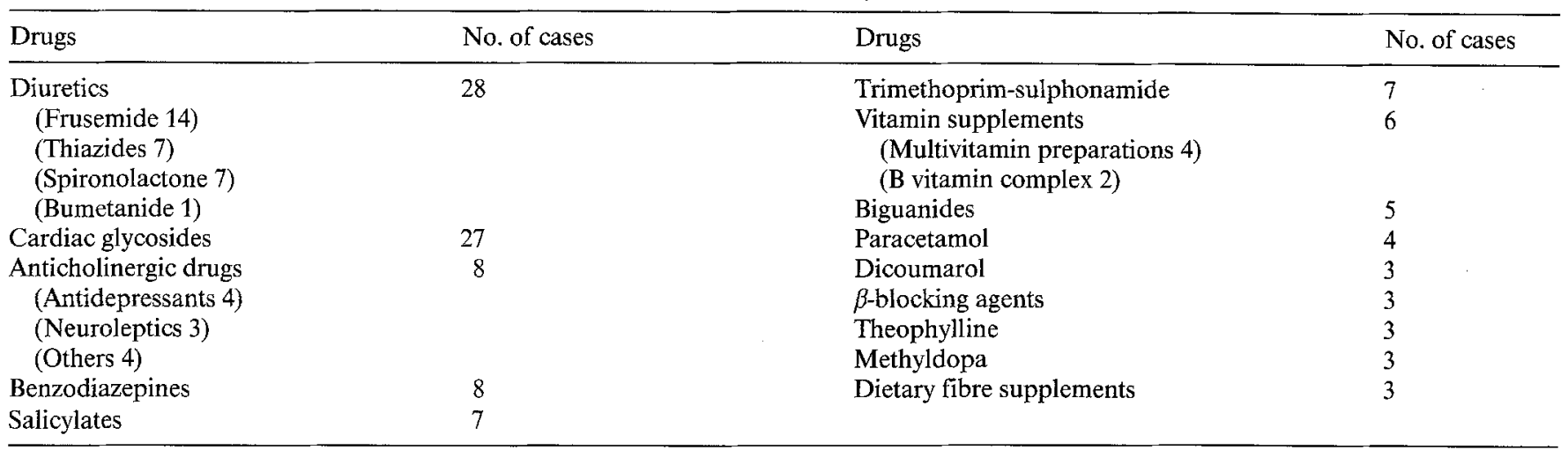

In several patients two or more of the additional drugs were used in combination

lished and the true frequency of this complication may thus be high.

Clarke and Campbell [16] observed eight hypoglycaemic episodes (four with coma) during 2 years' treatment of 134 diabetic patients with glibenclamide. In a slightly larger group treated with chlorpropamide, hypoglycaemia was observed in three patients (none with coma). Diabetic control was otherwise similar in the two groups.

The pharmacokinetic properties of glibenclamide are complex. There is evidence that the drug penetrates to a deep compartment $[3,27]$ from which it is only slowly eliminated; this may be of importance when long-term therapy is given with multiple daily doses. Moreover, steady state levels of glibenclamide [28] and other sulphonylureas $[29,30]$ vary more than tenfold in outpatients given the same daily dose. In view of the recent discovery of polymorphic drug oxidation [31], it is possible that glibenclamide might also exhibit a genetic polymorphism as it is mainly hydroxylated.

In clinical practice there is also little evidence that glibenclamide-induced hypoglycaemic events run a more benign course than those caused by other sulphonylureas, e.g. chlorpropamide. The mortality in our series of patients was high and in some patients hypoglycaemia persisted for 3 days despite continuous carbohydrate administration; in others several relapses were observed. It should however be noted that an overrepresentation of remarkable, serious and fatal cases is to be expected in spontaneous reports of adverse reactions. The median age of patients was high in the present series ( 75 years) and there was a striking preponderance of very old patients when compared with the glibenclamide-treated patients in the prescription survey. Clearly, glibenclamide treatment, if used at all, should be closely supervised in aged diabetic patients.

In the 15 patients with hepatic and/or renal impairment the hypoglycaemic events ran a considerably more serious course than in patients with normal liver and kidney functions: seven of them died and five had protracted hypoglycaemia. Hepatic insufficiency generally increases the sensitivity to sulphonylureas. Moreover, the disposition (both metabolism and binding) of glibenclamide might be disturbed by severe liver disease. Impaired renal function is frequently observed in patients with sulphonylurea-induced hypoglycaemia $[2,14$, 32]. Only minor amounts of glibenclamide are excreted unchanged by the kidney [3] but one of the main metabolites has been found to exert an hypoglycaemic action [33] and might accumulate in patients with decreased renal function. A decreased elimination of insulin and reduced glycogen stores in renal insufficiency may also be of importance $[34,35]$.

Enhanced effects of sulphonylureas are well known to be induced by some other drugs, e. g. salicylates, coumarin derivatives and some sulphonamides. Among these drugs, we encountered salicylates in seven patients $(12 \%)$ and dicoumarol in three. A trimethoprimsulphonamide combination was taken by seven patients. In six cases sulphamethoxazole was used which has previously been reported to prolong the elimination of tolbutamide [36]. The same may be true for glibenclamide.

The frequent use of digoxin and diuretics in the present series probably reflects the fact that many elderly diabetic patients suffer from circulatory disorders and are treated accordingly.

Among other agents previously not implicated in drug-induced hypoglycaemia three groups attract particular attention: anti-cholinergic drugs, vitamin $B$ and dietary fibres. Eight of the patients had taken drugs with anti-cholinergic action and only one of these responded instantly to glucose. There is theoretical [37] as well as experimental [38] support for the view that anticholinergic drugs worsen the course of hypoglycaemia. Many elderly people take vitamins and dietary fibre supplements. In patients taking sulphonylureas, a note of caution may be warranted because pyridoxine has been shown to reduce blood glucose in some diabetic patients [39] and dietary fibres have been introduced as an adjunct in the treatment of diabetes due to their hypoglycaemic action [40].

We conclude that glibenclamide should be used with great caution, especially in elderly patients. All dia- 
betic patients treated with sulphonylureas should be instructed on early symptoms of hypoglycaemia. They should be warned against excessive use of alcohol and salicylates, and we must keep potential interactions in mind when prescribing other drugs for them. Neither absence of apparent contributing factors nor low dosage of glibenclamide precludes serious hypoglycaemia.

Acknowledgements. Our sincere thanks are due to the many devoted physicians who have submitted reports on glibenclamide-associated hypoglycaemia to the Swedish Adverse Drug Reactions Advisory Committee or otherwise reported their experiences on this problem to us. Dr. S. Eriksson kindly provided statistical advice. This study was supported by grants from the Swedish Medical Research Council (19X-0544-02) and the Swedish Diabetes Association.

\section{References}

1. Shen S-W, Bressler R (1979) Clinical pharmacology of oral antidiabetic agents. N Engl J Med 296: 493-497 and 787-793

2. Seltzer HS (1972) Drug-induced hypoglycemia. A review based on 473 cases. Diabetes 21: $955-966$

3. Balant L, Fabre J, Zahnd GR (1975) Comparison of the pharmacokinetics of glipizide and glibenclamide in man. Eur J Clin Pharmacol 8: 63-69

4. Sartor G, Melander A, Scherstén B, Wåhlin-Boll E (1980) Comparative single-dose kinetics and effects of four sulfonylureas in healthy volunteers. Acta Med Scand 208: 301-307

5. National Corporation of Swedish Pharmacies (1975-1980) Statistical reports of drug sales and prescriptions (annual publications). Läkemedelsstatistik AB, Stockholm

6. Lunde PKM, Baksaas I, Halse M, Halvorsen T, Strømnes B, Öydvin K (1978) Methodology in drug utilization studies. The need for a uniform drug classification and a comparable unit of measurements. In: Bergman U, Grimsson A, Wahba AHW, Westerholm B (eds). Drug utilization studies - Methods and applications, European Series No.8. WHO Regional Publications, Copenhagen pp 17-28

7. Kristoferson K, Wessling A (1977) Tre års receptundersökningar. Svensk Farmaceutisk Tidskrift $81: 309-316$

8. Böttiger LE, Westerholm B (1973) Drug-induced blood dyscrasias in Sweden. Br Med J 3: 339-342

9. Arneborn P, Palmblad J (1978) Drug-induced neutropenia in the Stockholm region 1973-75: Frequency and causes. Acta Med Scand 204: 283-286

10. Seltzer HS (1979) Severe drug-induced hypoglycemia: a review. Compr Therapy 5: 21-29

11. Hasslacher C, Wahl P (1971) Häufigkeit und Schwere therapiebedingter Hypoglykämien bei Diabetikern. Deutsch Med Wochenschr 96: 1787-1791

12. Raymond JP, Chimènes H, Klotz HP (1971) Les dangers d'hypoglycémies sévères au Glibenclamide (Daonil ou Euglucan). A propos de 10 comas survenus en 6 mois. Diabète 19:31-32

13. Codaccioni J-L, Rubin P, Mattei A, Vague P (1971) Quatre hypoglycémies graves dont une mortelle au cours du traitement par Glibenclamides. Diabète 19: 37-41

14. Frerichs H, Deuticke U, Creutzfeldt W (1973) Nebenwirkungen der oralen Antidiabetika: Hypoglykämie. Med Klin 68: 363-370

15. De Vigan C, Delporte MP, Thomas M, Perrault M (1976) Les accidents hypoglycémiques des thérapeutiques orales du diabète. Nouv Presse Med 5:906-910

16. Clarke BF, Campbell IW (1975) Long-term comparative trial of glibenclamide and chlorpropamide in diet-failed, maturity-onset diabetics. Lancet 1: 246-248

17. Gutsche H, Höpker W, Boenicke G (1969) Ursachen und Verhütung von Hypoglykämien unter Glibenclamide. Med Welt 20: $1876-1880$

18. Gottesbüren H, Gerdes H, Littman KP (1970) Schwere Hypoglykämien nach Glibenclamide. Verh Dtsch Ges Inn Med 76:433-435
19. Nistrup Madsen S, Persson I (1970) Behandling med et nyt antidiabetikum: glybenklamid. (Treatment with a new antidiabetic, Glybenclamide). Ugeskr Laeger 132: 143-147

20. Carlström S, Monti M (1973) Hypoglykämi vid behandling av diabetes med glibenklamid (Hypoglycemia in the treatment of diabetes with glibenclamide). Läkartidningen 70: 1020-1022

21. Hildick-Smith M (1974) Epilepsy in the elderly. Age Ageing 3: 203-208

22. Cuartero AR, Medina JV (1976) Coma hipoglucémico por antidiabéticos orales. Rev Clin Esp 140: 579-583

23. Ahmed A (1976) Hypoglycaemic coma with Daonil. Indian J Med Sci 30: 140

24. Talseth T, Eika C (1978) Langvarig glibenklamid-indusert hypoglykemi. Tidskr Nor Laegeforen 98: 949-950

25. Kalimo H, Olsson Y (1980) Effects of severe hypoglycemia on the human brain. Neuropathological case reports. Acta Neurol Scand 62: 345-356

26. Asplund K, Lithner F (1979) Svår hypoglykämi utlöst av glibenklamid (Severe hypoglycaemia induced by glibenclamide). Läkartidningen 76:967-968

27. Balant L, Zahnd GR, Weber F, Fabrie J (1977) Behaviour of glibenclamide on repeated administration to diabetic patients. Euro J Clin Pharmacol 11: 19-25

28. Sartor G, Melander A, Scherstén B, Wåhlin-Boll E (1980) Serum glibenclamide in diabetic patients, and influence of food on the kinetics and effects of glibenclamide. Diabetologia 18: 17-22

29. Melander A, Sartor G. Wåhlin E, Scherstén B, Bitzén P-O (1978) Serum tolbutamide and chlorpropamide concentrations in patients with diabetes mellitus. Br Med J 1: 142-144

30. Bergman U, Christenson I, Jansson B, Wiholm B-E, Östman J (1980) Wide variations in serum chlorpropamide concentrations among out-patients. Eur J Clin Pharmacol 18: 165-169

31. Eichelbaum M (1982) Defective oxidation of drugs: Kinetic and therapeutic implications. Clin Pharmacokin 7:1-22

32. Berger W (1974) Hypoglykämien unter der Behandlung mit Sulfonylharnstoffen. In: Belser FG, Froesch ER (eds) Diabetische Enteropathie - Hypoglykämien. Hans Huber, Bern Stuttgart Wien, pp 48-65

33. Balant L, Fabre J, Loutan L, Samini H (1979) Does 4-transhydroxy-glibenclamide show hypoglycemic activity? Arzneim Forsch 29: 162-163

34. O'Brien JP, Sharpe AR (1967) The influence of renal disease on the insulin I-131 disappearance curve in man. Metabolism 16: $76-83$

35. Lowrie EG, Soeldner JS, Hampers CL, Merril JP (1970) Glucose metabolism and insulin secretion in uremic, prediabetic and normal subjects. J Lab Clin Med 76: 603-615

36. Hansen JM, Christensen LK (1977) Drug interactions with oral sulphonylurea drugs. Drugs 13: 24-34

37. Blass JP, Gibson GE (1978) Cholinergic systems and disorders of carbohydrate catabolism. Adv Behav Biol 24: 791-803

38. Gibson GE, Blass JP (1976) Impaired synthesis of acetylcholine in brain accompanying mild hypoxia and hypoglycemia. J Neurochem 27: 37-42

39. Coelingh Bennink HJT, Schreurs WHP (1975) Improvement of oral glucose tolerance in gestational diabetes by pyridoxine. $\mathrm{Br}$ Med J 3: 13-15

40. Jenkins DJA, Leeds AR, Gassull MA, Wolever TMS, Goff DV, Alberti KG, Hockaday TDR (1976) Unabsorbable carbohydrates and diabetes: Decreased post-prandial hyperglycaemia. Lancet 2: 172-174

Received: 8 February 1982

and in revised form: 11 April 1983

Dr. Kjell Asplund

Department of Medicine

Umeå University Hospital

S-901 85 Umeå

Sweden 